\title{
Soil organic matter: application for heavy metal source diagnostics in sediments of the Middleton River, bayelsa state, Nigeria
}

\begin{abstract}
The chemical species of metals (Fe, $\mathrm{Ni}$ and $\mathrm{Pb}$ ) in the Middleton River were determined and their relationship with soil organic matter was established with a view to identifying the likely source (natural or anthropogenic) of these metals within the water body. The GBC Avanta PM AAS was used to quantify the levels of metals in each fraction. The most important fractions of iron, nickel and lead were found to be the poorly mobile and immobile metal species. The metals were most affiliated to the residual fractions thereby depicting that they are from the natural environment. However, the dry season depicted the tendency for nickel and lead to become bioavailable and potentially toxic as significant levels of the metals were superficially adsorbed on the surface of sediment colloids where they are readily redistributed within the water column as water soluble fractions. Sediment organic matter in the Middleton River may be mainly composed of soluble fulvic acids which may have aided metal desorption. The order of prevalence for metal speciation in the dry season was organic matter bound $(24.7 \%)$, residual $(67.6 \%)$ and organic matter bound fraction $(34.3 \%)$ for iron, nickel and lead respectively. The wet season revealed the prevalence of amorphous Fe-oxide $(28.6 \%)$, residual fraction $(78.0 \%)$ and organic matter bound fraction $(30.4 \%)$ for iron, nickel and lead respectively, thereby, portending that the metals are emanating from the natural environment. On the other hand, the readily transportable water soluble fractions depicted significant metal retention levels of $(19.1 \%)$ and $(12.5 \%)$ for nickel and lead during the dry season thereby portending the contribution of anthropogenic inputs; most likely from activities of oil bunkers, occasional oil spill from worn-out pipeline joints and boat transportation. Metal mobility factors depicted the trends $(\mathrm{Ni}>\mathrm{Pb}>\mathrm{Fe})$ for the impacted areas across the dry and wet seasons. The control locations also depicted $(\mathrm{Pb}>\mathrm{Ni}>\mathrm{Fe})$ and $(\mathrm{Ni}>\mathrm{Fe}>\mathrm{Pb})$ during the dry and wet seasons respectively. Overall, $\mathrm{Ni}$ and $\mathrm{Pb}$ may possess the most potential to be bioavailable in the Middleton River estuary.
\end{abstract}

Keywords: speciation, chemical mobility, bioavailability, Middleton River
Volume 4 Issue 6 - 2018

\author{
Aigberua AO \\ Department of Chemical Sciences, Niger Delta University, \\ Nigeria
}

Correspondence: Aigberua AO, Department of Chemical Sciences, Faculty of Science, Niger Delta University, Wilberforce Island, Bayelsa State, Nigeria, Email ozadee I0I@gmail.com

Received: October 30, 2018 | Published: December 10, 2018

\section{Introduction}

Heavy metal contaminants may emanate from either natural or anthropogenic sources and infiltrate the aquatic environment. Some of the natural sources include weathered rocks, atmospheric deposits from suspended particulate matter or volcanic eruptions. Near and on-shore anthropogenic activities such as indiscriminate discharge of industrial and municipal sewage effluents into water bodies, gaseous emissions from water transport, agricultural runoffs, amongst others can contribute significant heavy metal burden to an aquatic system. Heavy metals can be found to either strongly adhere within the interstitial matrices of under-water sediments where they can become chelated to organic matter or adsorb superficially on the surface of sediment colloids where they can be readily redistributed within the water column in the event of environmental disturbances. Heavy metals can be classified as essential (macro and micro) and non-essential (toxic) to living organisms. Heavy metals have been identified as significant micropollutants for invertebrates, fishes and humans and have been known to depict severe effects on the ecological balance of environment and multiplicity of aquatic organisms. ${ }^{1-3}$ The concentration and distribution of heavy metals in sediments around inhabited areas could be used to examine anthropogenic impacts on ecosystems and aid in the evaluation of threats posed by human waste discharges. ${ }^{3-5}$ The eventual discharge of effluents by industries and other anthropogenic activities in and around creeks and rivers represents a crucial environmental challenge particularly in developing areas such as the Niger Delta in Nigeria. ${ }^{3}$ As an example, oil spills could cause fire and result in the depletion of wildlife, vegetation, loss of high-yielding soil, pollution of air and drinking water, deterioration of farmland and devastation of aquatic ecosystems, ${ }^{6,7}$ loss of lives, farmland and other infrastructural resources. ${ }^{7,8}$ Several heavy metals are associated with crude oil including lead, cadmium, copper and zinc. ${ }^{7,9}$ Elevated levels of iron can result from the discharge of industrial effluents, the corrosion of tanks, piping and other equipment and installations containing iron. ${ }^{10}$ Nickel enters surface waters naturally in the form of particulate matter in rain water, the dissolution of primary bedrock materials and secondary oil phases. Within aquatic systems, nickel typically occurs as soluble salts adsorbed onto, or associated with, clay particles, organic matter, and other substances. ${ }^{11}$ Lead can enter natural waters from industrial wastewaters, corrosion of tanks and piping, as well as materials made from lead. Small amounts of lead can come from the soil. ${ }^{12}$ Organic content and sediment granulometry are important for lead sorption on bottom sediments, while a $\mathrm{pH}>6$ in the absence of dissolved complex compounds can lead to adsorption in sediments with an acidic environment favouring a strong adsorption of lead on 
humic substances. ${ }^{13}$ Metal speciation includes the chemical form of the metal in the soil solution, either as a free ion or complexed to a ligand, in the gaseous phase and distributed amongst solid phases within the soil. However, the long-term bioavailability of metals to humans and other organisms is determined by the re-supply of the metal to the mobile pool (soil solution) from more stable phases (metals in and associated with solid species). ${ }^{14}$

Soil organic matter (SOM) refers to the non-living organic material in the soil, which makes up by far the major portion of the total organic components. ${ }^{15}$ It can be of plants, animal or microbial origin and may be fresh and highly decomposed and transformed. Increasing the amount of organic matter in the soil helps to minimize the absorption of heavy metals by plants. Land rich in organic matter actively retains metallic elements. ${ }^{16}$ The amount of available soil organic matter significantly influences metal bioavailability since it is considered as the most important soil constituent that retains heavy metals. Generally, fulvic-metal complexes are soluble, while humic-metal complexes are insoluble. ${ }^{17}$ Ross $^{18}$ had earlier pointed out that soil organic matter is composed of large molecular weight humin and humic acid compounds and lower molecular weight fulvic acids. Changes in chemical properties of soils affect concentration of free metals and result in changes in their availability for plants. ${ }^{19}$ Bioavailability is controlled by a number of soil properties which regulate these processes. Generally, conditions resulting in less fixation of metal in soil (e.g. low $\mathrm{pH}$, low organic matter content) lead to greater bioavailability to living organisms. Influential soil properties include $\mathrm{pH}$, organic matter content, cation exchange capacity, redox conditions, the presence of hydrous hydroxides, and other ions..$^{20}$ The use of nine-stage multi-step extraction scheme as previously used by Olutona et al. ${ }^{21}$ has been adopted in this study. The extraction procedures have been used to understand the concept of bioavailability, mobility and potential toxicity of iron, nickel and lead in the Middleton river system. The fate and chemical behaviour of metals and their bioavailability in the environment results in the qualification and quantification of different forms of the elements. The present study was necessitated by the quest to understand the role of organic matter in the diagnosis of elemental species that are found in sediments of the Middleton River system and the effect of seasonal variations on their potential toxicity within the aquatic ecosystem.

\section{Materials and methods}

\section{Study area}

Middleton River is a creek located in the Southern Ijaw local government area of Bayelsa state, the river is also referred to as Middleton creek, Middleton or Sagpetoru River. Its geographical coordinates lie within the latitude $4^{\circ} 30^{\prime} 30.49$ ' $\mathrm{N}$ and longitude $5^{\circ} 43$ ' 39.94" $\mathrm{E}$ and is bound by neighbouring communities such as Babatoriagbene, Oporogbene, Kulama, Jituagbene, Beyentoro amongst others. The Middleton River is home to numerous oil and gas installations within the Niger Delta area as it is dotted with a number of oil wells and manifolds that serve as supply lines to neighbouring oil flow stations. The area is therefore characterized by a network of underwater oil pipelines that move crude oil and gas; oil bunkering activities are predominant in this area while pipeline vandalism is not uncommon. The river is tidal and sometimes overflows, driving spilt crude into surrounding freshwater, mangrove swamps and mudflats, hence, the aquatic environment intermittently reflects oil sheen. In addition, other forms of indiscriminate and uncontrolled municipal discharges negatively impact on the overall quality of the aquatic environment. ${ }^{22}$

\section{Field sampling}

Sediment samples were collected in a manner that reflected the oil and gas activities within the river. Five (5) sampling points were established from potential point sources of oil pollution while two (2) control points were sampled at about $1 \mathrm{~km}$ upstream (C1) and $2 \mathrm{~km}$ downstream (C2) distances from pollution point sources. An Eckmann grab was deployed to collect bottom sediments and each sampling point was geo-referenced with a hand-held Garmin Etrex model GPS; the coordinates were recorded as: A (N04 $\left.41^{\prime} 48.1^{\prime \prime}, \mathrm{E} 005^{\circ} 55^{\prime} 20.0^{\prime \prime}\right)$,

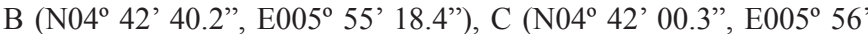

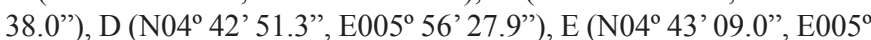
$56^{\prime}$ 11.2"), Control 1 (N04' 43' 58.3", E005 56' 41.5") and Control 2 (N04' 40'.068", E005 53'.018”). Triplicate samples were collected for each sampling point and transferred into pre-cleaned polyethylene bags before been stored in an ice chest. ${ }^{23}$

\section{Sample pre-treatment, analysis and quality assurance/ control protocol}

Sediment samples were air-dried at room temperature, homogenized by grinding and sieved through a $2 \mathrm{~mm}$ mesh size sieve before being further sub sampled and labelled in plastic vials. Glassware was properly cleaned, oven-dried and cooled in a desiccator. Reagent blank was prepared for each fraction of the sequential extraction. A series of working standard solutions of 0.5 , $1,2,5,10$ and $100 \mathrm{mg} / 1$ was prepared from the stock standard solution $(1000 \mathrm{mg} / 1$ of an Accustandard solution (USA)) of each test metal; this was done by diluting known volumes of the stock solution in 100 $\mathrm{ml}$ volumetric flasks using distilled water. Standard solutions were used to calibrate the Flame Atomic Absorption Spectrophotometer (FAAS). During analysis, method blanks and standard solutions were aspirated at the start, midpoint and end of each metal run as part of the quality assurance protocol. The following instrument wavelengths were applied: $\mathrm{Fe}(372.0 \mathrm{~nm})$, Ni (232.0nm), Pb (217.0nm).

\section{Reagents and chemicals}

The reagents and chemicals used were of analytical grade, some of which included: ammonium nitrate (Analytical Reagent, Yueqiao chemicals, China), ammonium nitrate (Analytical Reagent, Yueqiao chemicals, China), 96\% glacial acetic acid (Riedel-De Haen, Germany), hydroxylamine hydrochloride (Analytical Reagent, Guangdong Guanghua Sci-Tech Co., Ltd Shantou, China), EDTA Disodium salt (Analytical Reagent, Interchem Europe (UK) Ltd), ammonium oxalate (LabTech Chemicals, India), ascorbic acid (BDH Chemicals Ltd, Poole England), hydrofluoric acid (BDH Chemicals Ltd, Poole England), Hydrofluoric acid (BDH Chemicals Ltd, Poole England), 65\% nitric acid (Riedel-De Haen, Germany), 37\% hydrochloric acid (Sigma-Aldrich Chemicals, USA), sodium hexametaphosphate (Analytical Reagents - Cartivalues Scientific Enterprises, (Singapore) PTE. Ltd), potassium dichromate (Analytical Reagent, Kermel Colmar, France), sulphuric acid (BDH Chemicals Ltd, Poole England), 1,10-phenanthroline hydrate (Hopkins \& Williams, Chadwell Health Essex, UK) and ferrous sulphate (Analytical Reagent, Kermel Colmar, France). All standard solutions were prepared using distilled water; working standards of the ten (10) metals to be determined were prepared by diluting different known volumes of their stock solutions $(1,000 \mathrm{mg} / \mathrm{l})$. 


\section{Sequential extraction of heavy metals}

The nine-stage sequential extraction scheme for metal fractionation reported by Olutona et al. ${ }^{21}$ was adopted. In this scheme, heavy metals were separated into nine operationally defined fractions $(\mathrm{F})$ : water soluble (F1), exchangeable (F2), bound to carbonate (F3), plant available (F4), bound to $\mathrm{Mn}$ (F5), bound to amorphous Fe oxide (F6), bound to crystalline oxide (F7), bound to organic matter (F8), and residual fraction (F9). One gram dry weight of each sediment sample was weighed and subjected to a nine-stage sequential extraction process using different extracting solutions as applicable for each extraction step. Distilled water was used to wash the residues following each extraction phase in order to ensure selective dissolution and to avoid possible cross-contamination between the different extraction solutions. All samples were run in triplicate; the detailed analytical protocol adopted is as follows:

\section{Fraction I:Water soluble metals}

Water soluble metals were extracted with a solution of $50 \mathrm{ml}$ distilled water at $\mathrm{pH} 7.0$ and at $28^{\circ} \mathrm{C}$ for $2 \mathrm{~h}$.

\section{Fraction 2: Exchangeable metals}

The residue from (water soluble metals) was extracted with $25 \mathrm{ml}$ of $1.0 \mathrm{M} \mathrm{NH}_{4} \mathrm{COOCH}_{3}(\mathrm{pH}=7.0)$. The suspension was agitated for $30 \mathrm{~min}$ at $28^{\circ} \mathrm{C}$.

\section{Fraction 3: Metals bound to carbonate}

The residue from (exchangeable metals) was extracted with $3 \mathrm{M}$ sodium acetate solution $\left(\mathrm{CH}_{3} \mathrm{COONa}\right)$ adjusted to $\mathrm{pH} 5.0$ with acetic acid $\left(\mathrm{CH}_{3} \mathrm{COOH}\right)$. The suspension was agitated for $5 \mathrm{~h}$.

\section{Fraction 4: Plant available metals}

The residue from (metals bound to carbonate) was extracted by shaking with a solution mixture consisting $50 \mathrm{ml}$ of $0.025 \mathrm{M} \mathrm{HCI}+$ $0.05 \mathrm{M} \mathrm{H}_{2} \mathrm{SO}_{4}$ for $30 \mathrm{~min}$ at $28^{\circ} \mathrm{C}$.

\section{Fraction 5: Metals bound to Mn-oxide}

The residue from (plant available metals) was shaken for $30 \mathrm{~min}$ at $28^{\circ} \mathrm{C}$ with a solution of $25 \mathrm{ml} 0.1 \mathrm{M}$ hydroxylamine hydrochloride $\left(\mathrm{NH}_{2} \mathrm{OH} . \mathrm{HCl}\right)$ in $25 \%$ acetic acid $\left(\mathrm{CH}_{3} \mathrm{COOH}\right)$ (pH 2 to 3 ).

\section{Fraction 6: Metals bound to amorphous Fe-oxide}

The residue from (Mn-oxide bound metals) was extracted with 25 $\mathrm{ml}$ of $0.2 \mathrm{M}$ Ammonium oxalate $\left[\left(\mathrm{NH}_{4}\right)_{2} \mathrm{C}_{2} \mathrm{O}_{4}\right](\mathrm{pH} 3.0)$ for $30 \mathrm{~min}$ at $50^{\circ} \mathrm{C}$ using a water bath with occasional stirring.

\section{Fraction 7: Metals bound to crystalline Fe-oxide}

The residue from (amorphous Fe-oxide bound metals) was extracted using a mixture of $0.2 \mathrm{M}$ Ammonium oxalate $\left[\left(\mathrm{NH}_{4}\right)_{2} \mathrm{C}_{2} \mathrm{O}_{4}\right]$ and $0.1 \mathrm{M}$ ascorbic acid $(\mathrm{pH} 3.25)$ and it was heated in a water bath with occasional stirring at $100^{\circ} \mathrm{C}$ for $30 \mathrm{~min}$.

\section{Fraction 8: Metals bound to organic matter}

The residue from (crystalline $\mathrm{Fe}$-oxide bound metals) was extracted with $10 \mathrm{ml}$ of $0.02 \mathrm{M} \mathrm{HNO}_{3}$ and $15 \mathrm{ml}$ of $30 \% \mathrm{H}_{2} \mathrm{O}_{2}$ (adjusted to $\mathrm{pH}$ 2 with $\mathrm{HNO}_{3}$ ). The mixture was then heated to $85^{\circ} \mathrm{C}$ for $5 \mathrm{~h}$ with occasional agitation. A second $15 \mathrm{ml}$ of $30 \% \mathrm{H}_{2} \mathrm{O}_{2}\left(\mathrm{pH} 2\right.$ with $\mathrm{HNO}_{3}$ ) was added and the mixture was heated again to $85^{\circ} \mathrm{C}$ for $3 \mathrm{~h}$ with intermittent agitation. After cooling, $5 \mathrm{ml}$ of $3.2 \mathrm{M} \mathrm{NH}_{4} \mathrm{COOCH}_{3}$ in
$20 \%(\mathrm{v} / \mathrm{v}) \mathrm{HNO}_{3}$ was added and the samples diluted to $20 \mathrm{ml}$ and agitated continuously for $30 \mathrm{~min}$.

\section{Fraction 9: Residual metals}

The residue from (organic matter bound metals) was digested with a mixture of concentrated $\mathrm{HF}, \mathrm{HNO}_{3}$ and $\mathrm{HCIO}_{4}$ for $8 \mathrm{~h}$.

\section{Results and discussion}

\section{Heavy metal speciation of bottom sediment}

The obtained data shows the heavy metal species or forms that characterize the bottom sediments of the Middleton River in Southern Ijaw LGA, Bayelsa State. The evaluated elements include: iron, nickel and lead. The identified metal species represents the inert or mobile metal fractions which either become bioavailable or potentially toxic within the aquatic ecosystem. Metal fractions were identified across the different sampling locations (impacted and control sites) along the river estuary. The effect of seasonal (dry and wet) variation was also evaluated. This data was generated from biannual sampling across the two months of March and August 2017 to reflect the dry and wet seasons respectively. A total of forty-two sediment samples were analysed for nine (9) metal fractions or forms by applying multi-step extraction procedures as adopted by Olutona et al. ${ }^{21}$ The results are presented in Figures 1 \& 2.

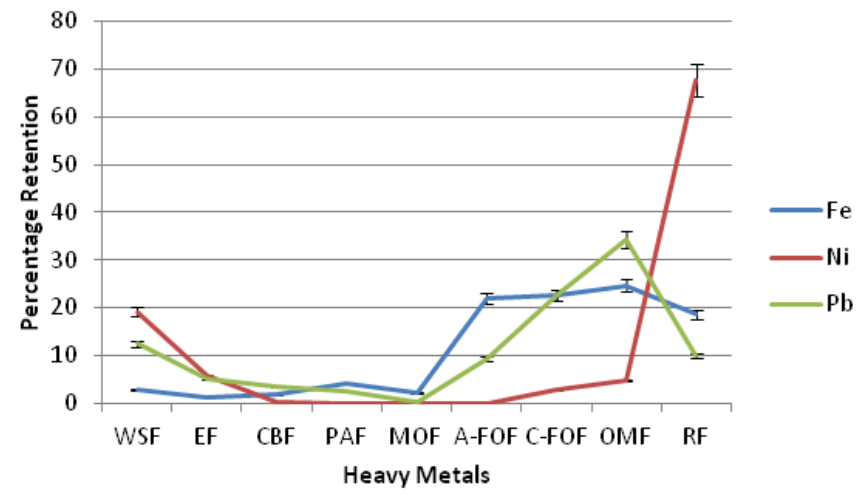

Figure I Percentage retention of heavy metal species in sediment fractions during the dry season.

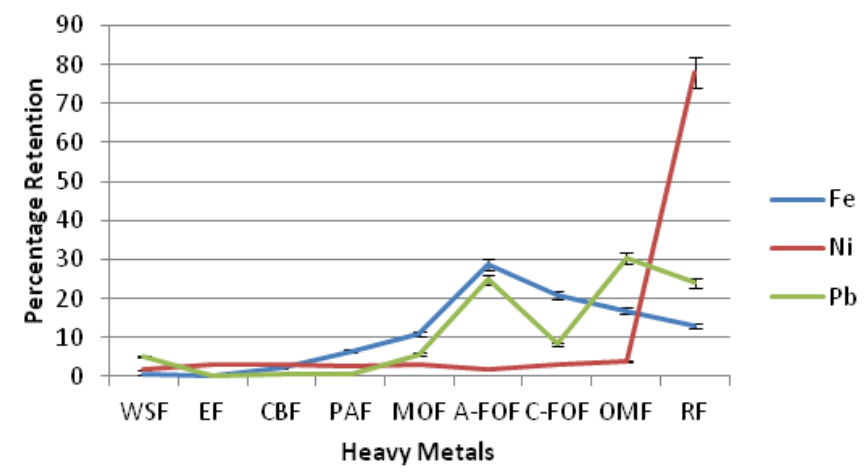

Figure 2 Percentage retention of heavy metal species in sediment fractions during the wet season.

Acronyms (refer to Figure 1 and 2): WSF=Water soluble fraction, $\mathrm{EF}=$ Exchangeable fraction, $\mathrm{CBF}=\mathrm{Carbonate}$ bound fraction, $\mathrm{PAF}=\mathrm{Plant}$ available fraction, $\mathrm{MOF}=\mathrm{Mn}$-oxide bound fraction, A-FOF=Amorphous Fe-oxide fraction, $\mathrm{C}-\mathrm{FOF}=\mathrm{Crystalline} \mathrm{Fe}$-oxide 
fraction, $\mathrm{OMF}=$ Organic matter bound fraction and $\mathrm{RF}=$ Residual fraction.

\section{Fractionation pattern of heavy metals in the different fractions (FI-F9)}

\section{Iron}

The dry season speciation pattern of iron depicted the prevalence of organic matter bound $(24.7 \%)$ and crystalline Fe-oxide fractions $(22.6 \%)$, other important fractions were the amorphous Fe-oxide $(22.0 \%)$ and residual fractions (18.6\%). On the other hand, the wet season revealed the prevalence of amorphous Fe-oxide (28.6\%) and crystalline Fe-oxide $(21.0 \%)$, followed by the organic matter bound $(16.9 \%)$ and residual fractions (13.0\%) (Figures $1 \& 2)$. Hence, iron was preferentially fractionated to the immobile phases. This finding was in agreement with Osakwe et al., ${ }^{24}$ that reported iron to be in the residual fractions of Imo river sediment. Leizou et al..$^{25}$ also reported iron to be preferentially bound to the residual and Fe/Mnoxide fractions of Pennington river sediment in Bayelsa state. The findings of this study partially agreed with Iwegbue et al., ${ }^{26}$ that iron was found in the Fe-Mn oxide, residual and easily exchangeable fractions of Ase river sediment. However, it disagreed with Olutona et al. ${ }^{21}$ that iron was associated with the exchangeable and carbonate fraction. Elevated levels of iron in the Middleton River may have resulted principally from natural sources as the prevalence of the element fractions were mainly within the interstitial matrices of the soil colloid. Notwithstanding, the corrosion of underlying crude oil pipelines and other equipment found across the study area could be contributed to the low levels found in the potentially toxic fractions.

\section{Nickel}

The dry season speciation pattern of nickel depicted that the prevalence of residual $(67.6 \%)$ and the water soluble fractions $(19.1 \%)$. However, nickel concentration during the wet season was largely due to the residual fraction (78.0\%) (Figures 1\&2). Findings from this study agreed with Tamunobereton-ari et al., ${ }^{27}$ that reported nickel in the residual fraction within the range of $65-85 \%$. Similarly, Iwegbue et al. ${ }^{26}$ observed that nickel was prevalent in the residual and organic matter bound fractions which are relatively immobile. Osakwe et al., ${ }^{24}$ had also found nickel to be associated with the carbonate, organic and residual fractions. The prevalence of nickel in the residual fractions may portend that it emanates from the natural environment, while its significant level in the water-soluble fractions depicts its adsorption to the surface of bottom sediment. Hence, the dry season reflects the contribution of anthropogenic inputs alongside the natural sources. The prevalence of nickel in the residual form may also result in its poor solubility and bioavailability within the Middleton River system.

\section{Lead}

During the dry season, the most important fractions of lead in the sediment were the organic matter bound $(34.3 \%)$ and crystalline Feoxide fractions $(22.6 \%)$. The contribution of water soluble fraction was quite significant $(12.5 \%)$. Overall, the poorly mobile fractions constituted the greater association of heavy metals. Similarly, the wet season depicted the prevalence of lead to the organic matter bound (30.4\%) and amorphous Fe-oxide fraction (24.9\%), while the residual fraction $(24.1 \%)$ closely followed (Figures $1 \& 2$ ). Osakwe et al., ${ }^{24}$ had reported lead to be mostly found in the residual fraction of Imo River. Tamunobereton-ari et al., ${ }^{27}$ had earlier reported lead to be about
$60-80 \%$ in the residual fraction of Okrika river sediment. However, Horsfall et al. ${ }^{28}$ had reported lead to appear in the first fraction exchangeable $(52.90 \%)$ for Okrika river sediment. The prevalence of lead in the inert fractions reflects its non-bioavailability in the aquatic environment. The association of lead to the residual fraction may be responsible for its poor solubility. Hence, lead concentration could mainly have been from the natural environment except for the dry season which revealed significant anthropogenic contribution which may have resulted from oil spill or run-off from the activities of oil bunkers.

\section{Mobility factors of heavy metals in bottom sediments of the Middleton River}

The operationally defined extraction sequence fractionates the heavy metals in the sediment in order of decreasing solubility. For a nine stage sequential extraction procedure, the water soluble, exchangeable and carbonate $(\mathrm{F} 1+\mathrm{F} 2+\mathrm{F} 3)$ fractions which are the early fractions reflect the most reactive and presumably the most mobile and potentially bioavailable fractions, ${ }^{29}$ (Table 1 ). The relative index of heavy metal mobility was calculated as a mobility factor (MF) (Kabala and Singh, 2001) on the basis of the equation:

$$
\begin{aligned}
& \qquad M F=\frac{F 1+F 2+F 3}{F 1+F 2+F 3+F 4+F 5+F 6+F 7+F 8+F 9} * 100 \\
& \text { F3 }=\text { Carbonate fraction } \\
& \text { F4 }=\text { Plant available fraction } \\
& \text { F5 }=\text { Mn-oxide fraction } \\
& \text { F6 }=\text { Amorphous Fe-oxide fraction } \\
& \text { F7 }=\text { Crystalline Fe-oxide fraction } \\
& \text { F8 }=\text { Organic matter bound fraction } \\
& \text { F9 }=\text { Residual fraction }
\end{aligned}
$$

A high mobility factor (MF) value for heavy metals in soil has been interpreted as evidence of relatively high mobility and biological availability. ${ }^{30}$

The mobility factors (MF) of the metals for the sediment sampling and control points are presented in Figures $3 \& 4$ for the dry and wet seasons respectively. The observed trend for the mobility factors of metals depicted $\mathrm{Ni}>\mathrm{Pb}>\mathrm{Fe}$ for the impacted areas across the dry and wet seasons while the control locations depicted $\mathrm{Pb}>\mathrm{Ni}>\mathrm{Fe}$ (dry season) and $\mathrm{Ni}>\mathrm{Fe}>\mathrm{Pb}$ (wet season). This finding partly agreed with that of Osakwe et al. ${ }^{24}$ where he reported mobility factor indices to depict the trends $(\mathrm{Ni}>\mathrm{Zn}>\mathrm{Cd}>\mathrm{Cu}>\mathrm{Pb}>\mathrm{Fe})$ and $(\mathrm{Cd}>\mathrm{Ni}>\mathrm{Zn}>\mathrm{Pb}>$ $\mathrm{Cu}>\mathrm{Fe}$ ) for bottom sediments of the Imo River system during the dry and wet seasons respectively. Heavy metal mobility factors were lower in the control locations as compared to the impacted sites during the dry and wet seasons except for iron which depicted greater mobility factor in the wet season for control locations as compared to the impacted site. The fact that marshlands exist within the sampling vicinity may have increased the levels of humic acids which contain dissolved salts of iron. Despite the abundance of iron in the environment, the poor relative abundance of mobile fractions as compared to the inert fractions may have led to its poor mobility and potential toxicity in the control locations and impacted sites during both seasons of study. These findings agreed with the previous work of Osakwe et al. ${ }^{24}$ 
Table I Operationally defined fraction and extracted components ${ }^{29}$

\begin{tabular}{|c|c|c|c|}
\hline Defined Fraction & Extracted Components & Physicochemical mobility & Potential bioavailability \\
\hline Water soluble & Free ions & Mobile & Easily available \\
\hline Exchangeable & $\begin{array}{l}\text { Exchangeable ions (metals retained by weak } \\
\text { electrostatic interactions) }\end{array}$ & Mobile & Easily available \\
\hline Acid soluble & Carbonates (for non-calcareous soils) & Easily mobilizable & Easily available \\
\hline Easily reducible & Mn oxyhydroxides & Readily mobilizable & Readily available \\
\hline Easily oxidizable & Metal-organic complexes & Readily mobilizable & Readily available \\
\hline Moderately reducible & Amorphous Fe (and Al) oxyhydroxides & Poorly mobilizable & Poorly available \\
\hline $\begin{array}{l}\text { Moderately and poorly } \\
\text { oxidizable }\end{array}$ & Refractory organic compounds and sulfides & Poorly mobilizable & Poorly available \\
\hline Poorly reducible & Crystalline Fe and Al oxyhydroxides & Poorly mobilizable & Poorly available \\
\hline Residual & $\begin{array}{l}\text { Mineral lattice (metals retained within the crystal } \\
\text { structure) }\end{array}$ & Immobile & Unavailable \\
\hline
\end{tabular}

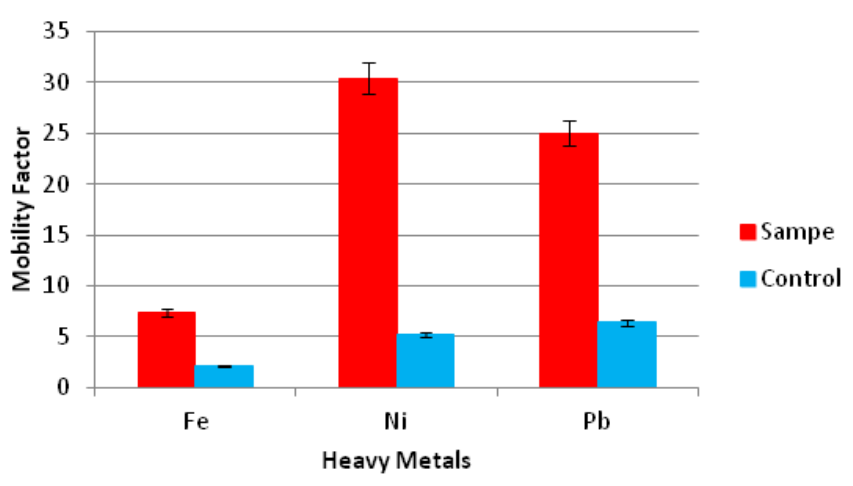

Figure 3 Heavy metal mobility factors during the dry season.

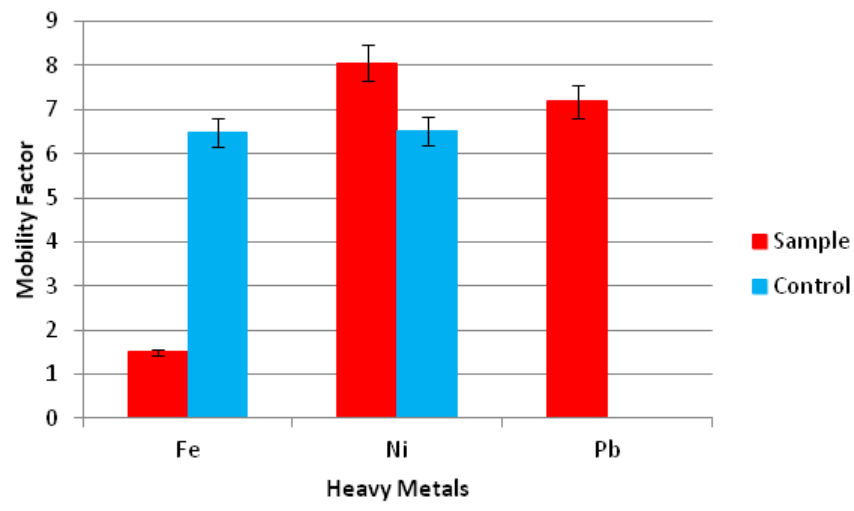

Figure 4 Heavy metal mobility factors during the wet season.

\section{Effect of sediment organic matter on mobility factor of heavy metals}

The bottom sediment was fairly rich in organic matter. Hence, it was expected that there will be metal chelation or release depending on the shift in organic matter level across both the dry and wet season. However, iron, nickel and lead showed an increasing mobility factor with increasing sediment organic matter (Figure 5). This depicts that the mobility of these metals in the sediment environment is favoured by increasing organic matter content; this may portend that they are from anthropogenic sources. Also, sediment organic matter in the Middleton River may be mainly composed of soluble fulvic-metal complexes (McBride, 1995).

\section{Metal mobility vs SOM level}

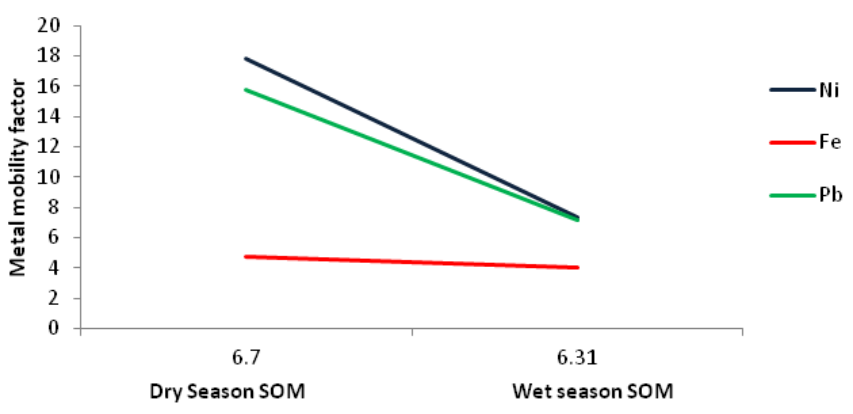

Figure 5 Seasonal effect of sediment organic matter (SOM) on metal mobility factor.

\section{Conclusion}

Results obtained from this study revealed that the most important fractions of iron, nickel and lead in the Middleton river system are the poorly mobile and immobile metal species. Among the metals studied, nickel was most affiliated to the residual fraction thereby depicting that the metal is predominantly from the natural environment as most of its fractions are likely to be embedded within the interstitial matrices of the sediment. However, the dry season depicted the tendency for nickel and lead to become bioavailable and potentially toxic. This is because significant levels of the metal were superficially adsorbed on the surface of sediment colloids where they are readily redistributed within the water column as water soluble fractions. This portends that the metals, though, mainly from the natural environment show significant contributions emanating from the activities of oil bunkers, occasional oil spill from worn-out joints of oil pipelines and boat transportation. Overall, relative mobility of these metals with increasing organic matter content may mean that they are from anthropogenic sources. This is likely, as they may have formed soluble fulvic-metal complexes that favour metal mobility. 


\section{Acknowledgments}

None.

\section{Conflicts of interest}

The author(s) declares that there is no conflicts of interest.

\section{References}

1. Farombi EO, Adelowo OA, Ajimoko YR. Biomarkers of oxidative stress and heavy metal levels as indicators of environmental pollution in African cat fish (Clarias gariepinus) from Nigeria Ogun River. Int $J$ Environ Res Publ Hlth. 2008;4:158-165.

2. Atici T, Ahiska S, Altindag A, et al. Ecological effects of some heavy metals $(\mathrm{Cd}, \mathrm{Pb}, \mathrm{Hg}, \mathrm{Cr})$ pollution of phytoplanktonic algae and zooplanktonic organisms in Sariyar Dam Reservoir in Turkey. Afr J Biotechnol. 2008;7:1972-1977.

3. Moslen M, Aigberua A. Sediment contamination and ecological risk assessment in the upper reaches of the Bonny Estuary, Niger Delta, Nigeria. Journal of Environmental Toxicology and Public Health. 2018;3:1-8.

4. de Mora S, Fowler SW, Wyse E, et al. Distribution of heavy metals in marine bivalves, fish and coastal sediments in the Gulf and Gulf of Oman. Mar Pollut Bul. 2004;49(5-6):410-424.

5. Zheng N, Wang QC, Liang ZZ, et al. Characterization of heavy metal concentrations in the sediments of three freshwater rivers in Huludao City, Northeast China. Environ Pollut. 2008;154(1):135-142.

6. Ogbeibu AE, Iyobosa SE. Illegal crude oil bunker in Nigeria: proximate and ultimate factors. Journal of Nigeria Environmental Society. 2013;7(4):1-18.

7. Aigberua AO, Ekubo AT, Inengite AK, et al. Assessment of some selected heavy metals and their pollution indices in an oil spill contaminated soil in the Niger Delta: a case of Rumuolukwu community. Biotechnol Res. 2017a;3(1):1-5.

8. Ambe BA, Eja IE, Agbor CE. Assessment of the impacts and people's perception of bush burning on the grasslands and montane ecosystems of the Obanliku Hills/Plateau, Cross River State, Nigeria. Journal of Natural Sciences Research. 2015;5(6):12-20.

9. Fatoba PO, Ogunkunle CO, Ihaza CO. Assessment of Metal Pollution of Soil and Diagnostic Species Associated with Oil Spills in the Niger Delta, Nigeria. Environmental Research, Engineering and Management. 2015;71(3):13-22.

10. Greenwood NN, Earnshaw A. Chemistry of the elements. 2nd ed. Butterworth-Heinemann, Oxford, 1998.

11. Eisler R. 'Nickel Hazards to Fish, Wildlife, and Invertebrates: A Synoptic Review'. MD: U.S. Geological Survey. (Contaminant Hazard Reviews Report No. 34), 1998.

12. Kabata Pendias A, Pendias H. Trace Metals in Soils and Plants. 3rd edn, CRC Press LLC, Boca Raton, New York: Washington; 2000.

13. Sauve S, Dumestre A, McBride MB, et al. Soil quality criteria using chemical speciation of $\mathrm{Pb} 2+$ and $\mathrm{Cu} 2+$. Environ. Toxicol Chem. 1998; 17:1481-1489.

14. Sauve S, Parker DR. Chemical speciation of trace elements in soil solution. In: Tabatabai MA, Sparks DL editor. Chemical processes in soils. SSSA Book series, SSSA, Madison, WI, 2005. p. 655-688.
15. Bigham JM. Methods of Soil Analysis Part 3 Chemical Methods. Sparks DL, Page AL, Helmke PA, editors.Wisconsin: Soil Science Society of America; 1996.

16. Fijalkowski K, Kacprzak M, Grobelak A, et al. The influence of selected soil parameters on the mobility of heavy metals in soils. Engineering and Environmental Protection. 2012;15(1):81-92.

17. McBride MB. Toxic Metal Accumulation from Agricultural Use of Sludge: Are USEPA Regulations Protective?' Journal of Environmental Quality. 1995;24(1):5-18.

18. Ross SM. 'Retention, Transformation and Mobility of Toxic Metals in Soils'. In: Ross SM. editor, Toxic Metals in Soil-Plant Systems. Chichester: John Wiley \& Sons; 1994.

19. Spurgeon DJ, Hopkin SP. Effects of variations of the organic matter content and $\mathrm{pH}$ of soils on the availability and toxicity of zinc to the earthworm Eisenia fetidia. Pedobiologia. 1996;40:80-96.

20. Intawongse M. Uptake of heavy metals by vegetable plants grown on contaminated soils, their bioavailability and speciation, 2007.

21. Olutona GE, Aribisala OG, Akintunde EA. A study of chemical speciation of metals in aquatic bottom sediment of Aiba reservoir, Iwo, Nigeria. African Journal of Environmental Science and Technology. 2012;6(8):312-321.

22. Aigberua A, Tarawou T, Abasi C. Spatial and Seasonal Assessment of Heavy Metals in Surface Waters of the Middleton River in the Niger Delta, Nigeria. International Journal of Natural Resource Ecology and Management. 2017b;2(5):94-98.

23. Aigberua AO, Tarawou JT, Abasi CY. Spatio-temporal dynamics of speciated metals and Arsenic and the effect of oxidation-reduction fluctuations on metal mobility in sediments of the Middleton River, Bayelsa State. J Appl Sci Environ Manage. 2018;22(9):1315-1320.

24. Osakwe JO, Adowei P, Horsfall MJ. Evaluation of Heavy Metal Species in Bottom Sediments from Imo River System, Southeastern Nigeria. Res J Chem Sci. 2014;4(6):23-30.

25. Leizou KE, Horsfall MJ, Spiff AI. Speciation of Some Heavy Metals in Sediments of the Pennington River, Bayelsa State, Nigeria. American Chemical Science Journal. 2015;5(3):238-246.

26. Iwegbue CMA, Emuh FN, Isirimah NO, et al. Fractionation, characterization and speciation of heavy metals in composts and compost-amended soils. African Journal of Biotechnology. 2007;6(2):67-78

27. Tamunoberetonari I, Omubo Pepple VB, Tamunoberetonari NA. Speciation of heavy metals $(\mathrm{Cu}, \mathrm{Pb}, \mathrm{Ni})$ pollutants and the vulnerability of groundwater resource in Okrika of Rivers State, Nigeria. Am J Sci Ind Res. 2011;2(1):69-77.

28. Horsfall MJ, Horsfall MN, Spiff AI. Speciation of Heavy Metals in Inter-tidal Sediments of the Okrika River System, Rivers State, Nigeria. Bull Chem Soc Ethiop. 1999;13(1):1-9.

29. Fedotov PS, Miro M. Fractionation and mobility of trace elements in soils and sediments, In: Violante, A., Huang, P. M., and Gadd, G. M. (eds). Biophysico-Chemical Processes of Heavy Metals and Metalloids in Soil Environments. Wiley-Jupac Series Vol 1, John Wiley \& Sons, NY: Hoboken; 2008. p. 467-520.

30. Kabala C, Singh BR. Fractionation and Mobility of copper, lead and zinc in vicinity of copper smelter. J Environ Qual. 2001;30(2):485-492. 